\title{
BMJ Open The magnitude of the association between smoking and the risk of developing cancer in Brazil: a multicenter study
}

\author{
Marcione Aparecida de Souza Moura, ${ }^{1}$ Anke Bergmann, ${ }^{1,2}$ \\ Suzana Sales de Aguiar, ${ }^{1}$ Luiz Claudio Santos Thuler ${ }^{1,3}$
}

To cite: Moura MA de S, Bergmann A, Aguiar SS de, et al. The magnitude of the association between smoking and the risk of developing cancer in Brazil: a multicenter study. BMJ Open 2014;4: e003736. doi:10.1136/ bmjopen-2013-003736

- Prepublication history and additional material for this paper is available online. To view these files please visit the journal online (http://dx.doi.org/10.1136/ bmjopen-2013-003736).

Received 17 September 2013 Revised 20 December 2013 Accepted 14 January 2014

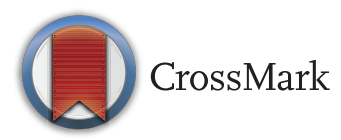

${ }^{1}$ Clinical Research and Technology Incorporation Coordination, Brazilian National Cancer Institute, Rio de Janeiro (RJ), Brazil

${ }^{2}$ Masters Program in Rehabilitation Science, University Center Augusto Motta-UNISUAM, Rio de Janeiro (RJ), Brazil

${ }^{3}$ Post Graduate Program in Neuroscience, Federal University of Rio de Janeiro State, Rio de Janeiro (RJ), Brazil

Correspondence to Dr Luiz Claudio Santos Thuler; Ithuler@inca.gov.br

\section{ABSTRACT}

Objectives: To estimate the magnitude of association and identify the aetiological fraction (AF) attributable to smoking in the development of different types of cancers in Brazil.

Setting: We conducted a case-control study, including 231102 patients registered in the Cancer Hospital Registries (CHR) in the period from 1998 to 2011.

Participants: A total of 204131 cancer cases relating to 30 topographies were compared with 26971 cases of non-melanoma skin cancer.

Primary and secondary outcome measures: Smoking exposure was considered at the time of hospital registration. We calculated $\mathrm{OR}$, unadjusted and adjusted for gender, age and alcohol consumption, with $95 \%$ Cls.

Results: After adjustment, the risk of developing cancer associated with smoking was very high (piriform sinus, bronchi and lung, larynx, hypopharynx, oropharynx and oral cavity), high (oesophagus and bladder), moderate (anus and anal canal stomach, nasal cavity, middle ear and paranasal sinuses, pancreas, nasopharynx, other parts of the biliary tract and kidney and low (liver, gall)). There was no association between smoking and cancers of the central nervous system and myeloid leukaemia. For thyroid cancer there was a decreased risk of developing the disease. The AF was higher than 50\% for hypopharynx, larynx, bronchi and lung, oropharynx, oral cavity and oesophagus cancers.

Conclusions: This study confirms a high risk of developing cancer of the hypopharynx, bronchi and lung, larynx, oropharynx and oral cavity, oesophagus and bladder cancer among smokers and establishes the AF attributable to smoking in the development of different types of cancer in Brazil.

\section{INTRODUCTION}

According to the WHO, cancer is the leading cause of death worldwide, with approximately 27 million incident cases, 17

\section{Strengths and limitations of this study}

- The limitation of this study is that it is based on the analysis of secondary data, with data collected in a large number of cancer treatment centres, making it difficult to standardise data collection. A strong point is that the association between smoking and cancer was adjusted for alcohol consumption. Even with these limitations, the opportunity to define the magnitude of the risk of developing cancer associated with tobacco use and the fraction of cancers that can be attributed to its consumption by a large Brazilian national study allowed, for the first time in the country, to give a comprehensive overview of this association.

million deaths and 75 million people living with the disease being estimated for the year $2030 .^{1}$

Smoking is the main risk factor for the development of many types of cancer. According to the International Agency for Research on Cancer (IARC), tobacco smoking is associated with cancers of the oral cavity, oropharynx, nasopharynx, hypopharynx, oesophagus, stomach, colon and rectum, liver, pancreas, nasal cavity and paranasal sinuses, larynx, lung, uterine cervix, ovary (mucinous), urinary bladder, kidney (body and pelvis), ureter and bone marrow (myeloid leukaemia). ${ }^{2}$ These tobacco-related cancers account for almost half of the global neoplastic disease burden. The $\mathrm{WHO}^{3}$ estimates that, each year, six million people die as a result of tobacco use and if this situation is not reversed in 2020, there will be about 7.5 million deaths annually.

In Brazil, according to data released by the Brazilian National Cancer Institute (NCI), tobacco use kills about 200000 people/year. ${ }^{4}$ Measures adopted in the country for tobacco control, contributed to the decline of $50 \%$ in 
the median prevalence of tobacco use in the past two decades. ${ }^{4-6}$ Brazil has a mixed population composition with varied genetic, epidemiological and sociodemographical characteristics, which may result in differential association between smoking and different types of cancer, and the empirical evidence of this association is relatively scarce in the country. Consequently, welldesigned epidemiological studies are necessary to assess the risk of disease and the fraction of cancers that can be attributed to tobacco use. Therefore, this study aims to estimate the magnitude of the association between smoking and the development of different types of cancers and to identify the aetiological fraction (AF) attributable to tobacco.

\section{MATERIALS AND METHODS}

An observational study was conducted using secondary data from Cancer Hospital Registries (CHR), provided by the Brazilian NCI through the Integrator CHR System, which gathers information on hospitalisations for cancer in Brazil. The data were taken in September 2011 and refer to cases for which the hospital provided the initial diagnosis of cancer and/or for which the hospital contributed to first course treatment (analytic cases), diagnosed between 1998 and 2011 and seen in 168 reference centres for cancer treatment, accredited by the Brazilian Government, in 24 Brazilian states.

We adopted a case-control study design. Cancer cases from 32 sites were compared with cases of nonmelanoma skin cancer, as they are not related to tobacco use and information was available in the database. We excluded patients younger than 18 years and older than 100 years, those with no information on gender and smoking, the main purpose of this research. Cancers with fewer than 50 cases with valid data were excluded, in order to render the analysis more precise.

The data set collected in each case includes variables such as demographics, tumour characteristics (cancer type, extent, location, etc), initial treatments and history of current alcohol consumption (more than three times per week, independent of amount consumed). The exposure variable was the report of habitual tobacco use and its derivatives at the time of hospital enrolment, categorised as yes or no.

Statistical analysis was performed using the PASW Statistics software, V.18. We conducted a descriptive analysis of the population. Percentages were calculated based on valid data (ie, missing data were excluded). Association between tobacco use and cancer occurrence was analysed using OR with 95\% CIs. In order to control for confounding factors or interactions, an adjusted analysis was performed considering age, gender and alcohol consumption, factors associated with both exposure and outcome. Variables completely outside the system of interest and variables only associated with the exposure or outcome were not included in the final model in order to avoid unnecessary regression adjustment and improve precision of estimators. The adjusted ORs were classified as: no association $(\mathrm{OR}<1)$; small effect or weak association (OR 1-1.5), medium or moderate association (OR 1.5-2.5); large or strong association (OR 2.5-4) and very large or very strong association $(\mathrm{OR}>4)$. For cancers associated with tobacco use, we calculated the $\mathrm{AF}$ or the population attributable risk fraction, in order to estimate the proportion of cancer cases that could be avoided if the population had not been exposed to tobacco. The AF was calculated using the formula: $\mathrm{AF}=\mathrm{Pc}(\mathrm{aOR}-1) / \mathrm{aOR}$, where $\mathrm{aOR}$ denotes the adjusted $\mathrm{OR}$ and $\mathrm{Pc}$ is the proportion of cases exposed. ${ }^{7}$ Once relative risk (RR) was replaced by OR the computing formula will approximate the excess fraction only insofar as the OR approximates the RR.

\section{RESULTS}

A total of 204131 cancer cases were compared with 26971 controls. In men, there was a predominance of prostate cancer, followed by bronchi and lung and oral cavity; in women, breast cancer, uterine cervix, and colon and rectum were more prevalent (table 1).

Regarding social and demographic variables, a high prevalence of patients aged 50 years or more $(71.4 \%)$, race/skin colour white $(59.0 \%)$, with eight or fewer years of schooling $(81.1 \%)$ and living with a partner $(60.1 \%)$ was observed. In addition, $29.2 \%$ had a history of alcohol and $47.9 \%$ reported tobacco consumption (table 2).

The risk of cancer associated with smoking, adjusted for gender, age and alcohol consumption, was very strong for cancers of the hypopharynx, bronchi and lung, larynx, oropharynx and oral cavity. Tobacco was classified as a strong risk factor for cancers of the oesophagus and bladder. A moderate risk was observed for cancers of the anus and anal canal, stomach, nasal cavity, middle ear and sinuses, pancreas, nasopharynx, other parts of the biliary tract and kidney. There was a weak association with liver cancer, gallbladder, and colon and rectum. There was no association between smoking and cancers of the central nervous system and myeloid leukaemia. For thyroid cancer, the effect of smoking was associated with a $20 \%$ reduction in the risk of developing the disease (table 3 ).

The AF results referring to cancer sites for both genders was above $50 \%$ for cancers of the piriform sinus, larynx, hypopharynx, bronchi and lung, oropharynx, oral cavity, and oesophagus. Intermediate fractions (10-50\%) were observed for cancers of the bladder, stomach, nasal cavity, middle ear and paranasal sinuses, anus and anal canal, nasopharynx, pancreas, other parts of biliary tract, kidney and liver. Fractions less than $10 \%$ were observed in cancers of the colon and rectum and bladder (table 3 ).

For women, intermediate aetiological fractions were observed for cervix $(20.1 \%)$, ovary $(19.9 \%)$ and vulva 
Table 1 Cancer sites according to gender $(n=231$ 102)

\begin{tabular}{|c|c|c|c|c|}
\hline Cancer site & ICD-O-3 & Male & Female & Total \\
\hline Oral cavity & C00-C08 & 9080 & 3108 & 12188 \\
\hline Oropharynx & C10 & 2458 & 435 & 2893 \\
\hline Nasopharynx & C11 & 740 & 312 & 1052 \\
\hline Piriform sinus & C12 & 651 & 59 & 710 \\
\hline Hypopharynx & C13 & 1429 & 168 & 1597 \\
\hline Oesophagus & C15 & 6884 & 2043 & 8927 \\
\hline Stomach & C16 & 6861 & 3508 & 10369 \\
\hline Colon and rectum & C18-C20 & 7813 & 7976 & 15789 \\
\hline Anus and anal canal & $\mathrm{C} 21$ & 375 & 1123 & 1498 \\
\hline Liver & $\mathrm{C} 22$ & 750 & 411 & 1161 \\
\hline Gallbladder & $\mathrm{C} 23$ & 129 & 432 & 561 \\
\hline Other parts of the biliary tract & $\mathrm{C} 24$ & 199 & 191 & 390 \\
\hline Pancreas & $\mathrm{C} 25$ & 918 & 804 & 1722 \\
\hline Nasal cavity, middle ear and sinuses & C30-C31 & 525 & 321 & 846 \\
\hline Larynx & C32 & 6574 & 993 & 7567 \\
\hline Bronchi and lung & C33-C34 & 10577 & 4930 & 15507 \\
\hline Myeloid leukaemia (morphology 9840-9930) & C42 & 1366 & 1100 & 2466 \\
\hline Kidney & C64 & 1318 & 942 & 2260 \\
\hline Bladder & C67 & 3265 & 1047 & 4312 \\
\hline Central nervous system & C70-C72 & 1394 & 1115 & 2509 \\
\hline Thyroid & C73 & 762 & 3470 & 4232 \\
\hline Breast & C50 & 484 & 45050 & 45534 \\
\hline Vulva & C51 & - & 1059 & 1059 \\
\hline Vagina & C52 & - & 329 & 329 \\
\hline Cervix & C53 & - & 28499 & 28499 \\
\hline Uterine body & C54 & - & 3607 & 3607 \\
\hline Ovary (mucinous subtype) & C56 & - & 340 & 340 \\
\hline Penis & $\mathrm{C} 60$ & 1048 & - & 1048 \\
\hline Prostate & C61 & 23991 & - & 23991 \\
\hline Testicle & C62 & 1168 & - & 1168 \\
\hline Skin (comparison group) & C44 & 14959 & 12012 & 26971 \\
\hline Total & - & 105718 & 125384 & 231102 \\
\hline
\end{tabular}

$(18.6 \%)$. Breast and vagina was found with lower aetiological fractions $(4.7 \%)$. In man, penis, testicles and prostate had fractions less than $10 \% \quad(8.3 \%, 5.4 \%$ and $4.1 \%$, respectively; data not shown). Stratification of the risk of developing cancer by gender showed that in men the highest risk was observed in the piriform sinus, bronchi and lung, hypopharynx, oropharynx and larynx (table 4). On the other hand, for women, the highest risk was for larynx, piriform sinus, bronchi and lung, oropharynx and oral cavity (table 5). With respect to specific cancers in men, low association was found for all sites analysed, except for cancers of the penis and testicles, which showed no statistically significant association with tobacco consumption (table 4). Among the woman specific cancers, the risk was considered to be moderate for cancers of the vulva, cervix and ovary and low for breast cancer. No statistical significance was found for cancers of the vagina and uterine body (table 5).

\section{DISCUSSION}

Although smoking is a well-established risk factor for the development of various types of cancer $^{3}$ the magnitude of the risk varies between studies according to race and income nation. ${ }^{8}$ There are few national publications that summarise the magnitude of the risk of developing the disease in view of the specificities of the Brazilian population.

In Brazil, a survey conducted before the beginning of this study, covering urban and rural areas, estimated smoking prevalence at 34.8\% (43.3\% among men and $27 \%$ among women). Surveys carried out in subsequent periods have shown lower prevalence, which is consistent with the figures obtained among controls in the present study. ${ }^{4}$

We observed very strong association between tobacco and oral cavity cancer, oropharynx, hypopharynx, larynx and bronchi/lung. In a European study, which analysed 2103 cases of squamous cell carcinoma of the upper aero digestive tract $^{9}$ slightly lower values than those in the current study were found for cancers of the oral cavity and oropharynx and higher values for hypopharynx and larynx. In a meta-analysis involving 254 studies, a similar RR for laryngeal cancer, bronchi/lung and oral cavity were observed. ${ }^{8}$

When analysing the risk of developing cancer of the bronchi and lung according to gender, the present study 
Table 2 Sociodemographic characteristics of the study population

\begin{tabular}{|c|c|c|c|c|c|c|c|c|c|c|c|c|}
\hline \multirow[b]{3}{*}{ Variables } & \multicolumn{6}{|l|}{ Cases } & \multicolumn{6}{|c|}{ Controls } \\
\hline & \multicolumn{2}{|l|}{$\overline{\text { Total }}$} & \multicolumn{2}{|l|}{ Male } & \multicolumn{2}{|l|}{ Female } & \multicolumn{2}{|l|}{$\overline{\text { Total }}$} & \multicolumn{2}{|l|}{ Male } & \multicolumn{2}{|l|}{ Female } \\
\hline & $\mathbf{N}$ & $\begin{array}{l}\text { Per } \\
\text { cent }\end{array}$ & $\mathbf{N}$ & $\begin{array}{l}\text { Per } \\
\text { cent }\end{array}$ & $\mathbf{N}$ & $\begin{array}{l}\text { Per } \\
\text { cent }\end{array}$ & $\mathbf{N}$ & $\begin{array}{l}\text { Per } \\
\text { cent }\end{array}$ & $\mathbf{N}$ & $\begin{array}{l}\text { Per } \\
\text { cent }\end{array}$ & $\mathbf{N}$ & $\begin{array}{l}\text { Per } \\
\text { cent }\end{array}$ \\
\hline \multicolumn{13}{|l|}{ Age (years) } \\
\hline $18-24$ & 2134 & 1.0 & 803 & 0.9 & 1331 & 1.2 & 153 & 0.6 & 82 & 0.5 & 71 & 0.6 \\
\hline $25-49$ & 56127 & 27.5 & 14321 & 15.8 & 41806 & 36.9 & 4761 & 17.7 & 2629 & 17.6 & 2132 & 17.7 \\
\hline $50-64$ & 73748 & 36.1 & 34658 & 38.2 & 39090 & 34.5 & 7849 & 29.1 & 4629 & 30.9 & 3220 & 26.8 \\
\hline$>65$ & 72119 & 35.3 & 40975 & 45.1 & 31144 & 27.5 & 14207 & 52.7 & 7618 & 50.9 & 6589 & 54.9 \\
\hline \multicolumn{13}{|l|}{ Race/skin colour } \\
\hline White & 108095 & 59.0 & 50489 & 61.8 & 57606 & 56.7 & 20068 & 80.6 & 11119 & 80.6 & 8949 & 80.6 \\
\hline Black/brown & 74208 & 40.5 & 30792 & 37.7 & 43415 & 42.8 & 4751 & 19.1 & 2624 & 19.0 & 2127 & 19.1 \\
\hline Indian/yellow & 955 & 0.5 & 431 & 0.5 & 524 & 0.5 & 83 & 0.3 & 50 & 0.4 & 33 & 0.3 \\
\hline \multicolumn{13}{|l|}{ Schooling } \\
\hline Illiterate & 21482 & 14.6 & 8752 & 13.9 & 12730 & 15.2 & 3183 & 15.8 & 1437 & 12.6 & 1746 & 20.0 \\
\hline$\leq 8$ years & 97588 & 66.5 & 43747 & 69.7 & 53811 & 64.1 & 13538 & 67.2 & 7798 & 68.4 & 5740 & 65.6 \\
\hline$>8$ years & 27670 & 18.9 & 10296 & 16.4 & 17374 & 20.7 & 3427 & 17.0 & 2162 & 19.0 & 1265 & 14.5 \\
\hline \multicolumn{13}{|l|}{ Marital status } \\
\hline With a partner & 118502 & 60.1 & 61721 & 70.8 & 56731 & 51.7 & 15760 & 60.2 & 10187 & 70.2 & 5573 & 47.7 \\
\hline Without a partner & 78551 & 39.9 & 25448 & 29.2 & 53103 & 48.3 & 10436 & 39.8 & 4332 & 29.8 & 6104 & 52.3 \\
\hline \multicolumn{13}{|l|}{ Region of residence } \\
\hline North & 15931 & 7.8 & 5533 & 6.1 & 10398 & 9.2 & 1016 & 3.8 & 597 & 4.0 & 419 & 3.5 \\
\hline Northeast & 34334 & 16.9 & 12431 & 13.7 & 21903 & 19.4 & 4998 & 18.6 & 2857 & 19.2 & 2141 & 17.9 \\
\hline Centre west & 4310 & 2.1 & 1734 & 1.9 & 2576 & 2.3 & 358 & 1.3 & 199 & 1.3 & 159 & 1.3 \\
\hline Southeast & 94134 & 46.3 & 42973 & 47.5 & 51161 & 45.3 & 12452 & 46.4 & 6932 & 46.5 & 5520 & 46.2 \\
\hline South & 54765 & 26.9 & 27767 & 30.7 & 26998 & 23.9 & 8040 & 29.9 & 4320 & 29.0 & 3720 & 31.1 \\
\hline \multicolumn{13}{|l|}{ Smoking } \\
\hline Yes & 97788 & 47.9 & 58342 & 64.3 & 39446 & 34.8 & 8344 & 30.9 & 6032 & 40.3 & 2312 & 19.2 \\
\hline No & 106343 & 52.1 & 32417 & 35.7 & 73926 & 65.2 & 18627 & 69.1 & 8927 & 59.7 & 9700 & 80.8 \\
\hline \multicolumn{13}{|l|}{ Alcohol consumption } \\
\hline Yes & 51752 & 29.2 & 38698 & 48.1 & 13054 & 13.5 & 4219 & 16.9 & 3600 & 26.3 & 619 & 5.5 \\
\hline No & 125684 & 70.8 & 41716 & 51.9 & 83968 & 86.5 & 20750 & 83.1 & 10106 & 73.7 & 10644 & 94.5 \\
\hline Total & 204131 & 100 & 90759 & 44.5 & 113372 & 55.5 & 26971 & 100 & 14959 & 55.5 & 12012 & 44.5 \\
\hline
\end{tabular}

found a higher risk associated with tobacco consumption for the female population. However, a distinct result was described in a study involving the Japanese population, which showed an RR 4.39 times greater for men and 2.79 for women. ${ }^{10}$

In the present study, we found moderate association between smoking and nasopharyngeal cancer. Discrepant results were reported in studies of other populations. For example, after adjusting for age, gender, smoking, drinking and family history of cancer, a higher risk was observed in the Chinese population ${ }^{11}$ while smoking conveyed no increased risk in an Italian population for undifferentiated subtypes of the disease but very high association for differentiated cases with consumption of more than 15 cigarettes/day. $^{12}$

Moderate risk was also demonstrated in this study for cases of cancers of the nasal cavity, middle ear and sinuses compared with the general population and for gender. This result was also revealed in another study ${ }^{13}$ that evaluated 14563 patients and showed a moderate risk for the general population and for men and women. It is noteworthy that to our knowledge, no study has considered the risk of piriform sinus cancer alone, although the present study showed very strong association between tobacco use and the development of cancer in this site.

Regarding the digestive tract, an elevated risk associated with smoking was observed for oesophageal cancer with a moderate risk for cancer of the stomach and pancreas. A recent meta-analysis described a lower risk for oesophageal cancer and a similar risk for cancers of the stomach and pancreas. ${ }^{8}$ In this study, a moderate risk was found in cancers of the anus and anal canal, but no publications discussing this association have been found. With regard to cases of cancer of the colon and rectum, the observed association was weak, which confirms the results of a review of 26 studies on the association between smoking and colorectal cancer. ${ }^{14}$ Furthermore, the authors also reported an association only for rectal cancer and no association for colon cancer. Similar figures to those described here were found in a European study involving 2741 patients. ${ }^{15}$ However, when the authors stratified by anatomic sites, proximal colon cancer showed an increased 
Table 3 Association between smoking and the development of different types of cancer and aetiological fraction (AF) that can be attributed to smoking in both genders

\begin{tabular}{|c|c|c|c|c|c|c|c|}
\hline \multirow[b]{2}{*}{ Cancer site } & \multicolumn{3}{|c|}{ Crude OR } & \multicolumn{3}{|c|}{ OR adjusted* } & \multirow[b]{2}{*}{$\mathrm{AF}(\%)$} \\
\hline & $\overline{\text { OR }}$ & $95 \% \mathrm{Cl}$ & p Value & $\overline{\text { OR }}$ & $95 \% \mathrm{Cl}$ & p Value & \\
\hline Oral cavity & 7.7 & 7.3 to 8.1 & $<0.001$ & 4.3 & 4.0 to 4.5 & $<0.001$ & 59.5 \\
\hline Oropharynx & 12.0 & 10.8 to 13.3 & $<0.001$ & 5.2 & 4.6 to 5.9 & $<0.001$ & 68.1 \\
\hline Nasopharynx & 2.4 & 2.1 to 2.7 & $<0.001$ & 1.8 & 1.5 to 2.0 & $<0.001$ & 22.9 \\
\hline Piriform sinus & 19.2 & 15.1 to 24.4 & $<0.001$ & 8.1 & 6.2 to 10.6 & $<0.001$ & 78.5 \\
\hline Hypopharynx & 13.4 & 11.6 to 15.5 & $<0.001$ & 5.7 & 4.8 to 6.7 & $<0.001$ & 70.7 \\
\hline Oesophagus & 8.0 & 7.6 to 8.5 & $<0.001$ & 4.0 & 3.7 to 4.2 & $<0.001$ & 58.7 \\
\hline Stomach & 2.6 & 2.4 to 2.3 & $<0.001$ & 1.9 & 1.8 to 2.0 & $<0.001$ & 25.3 \\
\hline Colon and rectum & 1.3 & 1.3 to 1.4 & $<0.001$ & 1.3 & 1.2 to 1.3 & $<0.001$ & 8.5 \\
\hline Anus and anal canal & 1.8 & 1.6 to 2.0 & $<0.001$ & 2.1 & 1.8 to 2.3 & $<0.001$ & 23.4 \\
\hline Liver & 2.2 & 2.0 to 2.5 & $<0.001$ & 1.4 & 1.2 to 1.6 & $<0.001$ & 14.1 \\
\hline Gallbladder & 1.2 & 0.9 to 1.5 & 0.621 & 1.3 & 1.0 to 1.6 & 0.03 & 7.4 \\
\hline Other parts of the biliary tract & 1.8 & 1.4 to 2.2 & $<0.001$ & 1.7 & 1.3 to 2.1 & $<0.001$ & 18.2 \\
\hline Pancreas & 1.9 & 1.8 to 2.1 & $<0.001$ & 1.8 & 1.6 to 2.0 & $<0.001$ & 20.7 \\
\hline Nasal cavity, middle ear and paranasal sinuses & 2.5 & 2.2 to 2.8 & $<0.001$ & 1.9 & 1.6 to 2.2 & $<0.001$ & 24.9 \\
\hline Larynx & 12.0 & 11.2 to 12.9 & $<0.001$ & 6.3 & 5.9 to 6.8 & $<0.001$ & 70.9 \\
\hline Bronchi and lung & 9.3 & 8.8 to 9.7 & $<0.001$ & 7.9 & 7.4 to 8.3 & $<0.001$ & 70.4 \\
\hline Kidney & 1.7 & 1.5 to 1.8 & $<0.001$ & 1.6 & 1.4 to 1.7 & $<0.001$ & 15.9 \\
\hline Bladder & 3.5 & 3.3 to 3.7 & $<0.001$ & 2.8 & 2.6 to 3.1 & $<0.001$ & 39.1 \\
\hline Central nervous system & 1.0 & 0.9 to 1.1 & 0.744 & 1.0 & 0.9 to 1.1 & 0.64 & - \\
\hline Thyroid & 0.5 & 0.5 to 0.6 & $<0.001$ & 0.8 & 0.7 to 0.8 & $<0.001$ & - \\
\hline Myeloid leukaemia & 1.0 & 1.0 to 1.1 & 0.213 & 1.0 & 0.9 to 1.1 & 0.91 & - \\
\hline
\end{tabular}

risk, whereas no significant increased risk was observed for distal colon cancer.

For neoplasms of the urinary tract, moderate association with smoking was found for cases of kidney cancer, with comparable figures in both genders. Similar findings were reported in a meta-analysis involving 24 epidemiological studies. ${ }^{16}$ The authors stressed that the risk was proportional to tobacco consumption for both genders. Regarding the cases of bladder cancer, strong association was found with smoking with similar results in men and women. A case-control study involving 1586 patients showed a moderate risk of cancer, with increasing values for low-grade superficial, high-grade superficial or invasive tumours. Furthermore, women were at increased risk for invasive types when they consumed similar amount of cigarettes to men. ${ }^{17}$

Although the authors of the present study have not identified specific studies with reference to the association between smoking and gallbladder cancer, the current results point to weak association in the general population, although when stratified by gender, the association was not significant for men and was weak for women. With respect to liver cancer, one meta-analysis evaluated the association with tobacco smoking and its development, finding a moderate risk in this disease, which supports the IARC conclusion. ${ }^{18}$ In the present study, we found a weak association, which corroborated the findings of a prospective cohort study conducted in Singapore with 394 patients with hepatocellular carcinoma. $^{19}$
The results of this study showed no association between smoking and the risk of developing cancer of the central nervous system and myeloid leukaemia. Similar findings were shown in a prospective cohort study that highlighted a lack of association with brain tumours. However, the authors showed statistically significant association for myeloid leukaemia, in contrast to the results presented here. ${ }^{20}$

Male genital tract cancers have not been listed ${ }^{2}$ as related to tobacco. A lack of association between these cancers and smoking was confirmed in the current study. For prostate cancer this study showed weak association with smoking. A large prospective cohort study found a decreased risk for non-advanced disease in current smokers, but an increased risk of fatal prostate cancer among smokers. $^{21}$

In assessing the association between smoking and developing woman specific cancers, we observed a scarcity of publications that addressed this issue in some tumour locations. For breast cancer, despite the large number of studies, the association remains controversial. Although it is known that cigarettes contain carcinogens that can increase the risk of developing the disease, its antiestrogen action may be a protective factor. In the present study, we found a weak association between smoking and breast cancer, a finding which is supported by a study which evaluated 1240 women diagnosed with invasive breast cancer and reported that consuming 10 or more cigarettes/day for up to 20 years increases the risk of breast cancer by $34 \% .^{22}$ In cases of cancer of the 
Table 4 Association between smoking and the development of different types of cancer in men

\begin{tabular}{|c|c|c|c|c|c|c|}
\hline \multirow[b]{2}{*}{ Cancer site } & \multicolumn{3}{|c|}{ Crude OR } & \multicolumn{3}{|c|}{ OR adjusted* } \\
\hline & $\overline{\text { OR }}$ & $95 \% \mathrm{Cl}$ & p Value & $\overline{\text { OR }}$ & $95 \% \mathrm{CI}$ & p Value \\
\hline Oral cavity & 7.8 & 7.3 to 8.3 & $<0.001$ & 4.4 & 4.1 to 4.8 & $<0.001$ \\
\hline Oropharynx & 10.2 & 9.0 to 11.6 & $<0.001$ & 5.3 & 4.6 to 6.1 & $<0.001$ \\
\hline Nasopharynx & 2.1 & 1.8 to 2.4 & $<0.001$ & 1.8 & 1.5 to 2.1 & $<0.001$ \\
\hline Piriform sinus & 14.1 & 10.8 to 18.3 & $<0.001$ & 7.8 & 5.9 to 10.5 & $<0.001$ \\
\hline Hypopharynx & 11.1 & 9.4 to 13.1 & $<0.001$ & 6.1 & 5.1 to 7.3 & $<0.001$ \\
\hline Oesophagus & 7.6 & 7.0 to 8.1 & $<0.001$ & 4.0 & 3.7 to 4.3 & $<0.001$ \\
\hline Stomach & 2.5 & 2.3 to 2.6 & $<0.001$ & 1.9 & 1.8 to 2.0 & $<0.001$ \\
\hline Colon and rectum & 1.4 & 1.4 to 1.5 & $<0.001$ & 1.3 & 1.2 to 1.4 & $<0.001$ \\
\hline Anus and anal canal & 2.2 & 1.8 to 2.7 & $<0.001$ & 2.1 & 1.6 to 2.7 & $<0.001$ \\
\hline Liver & 2.2 & 1.9 to 2.3 & $<0.001$ & 1.4 & 1.2 to 1.7 & $<0.001$ \\
\hline Gallbladder & 1.6 & 1.1 to 2.2 & 0.012 & 1.4 & 0.9 to 2.1 & 0.13 \\
\hline Other parts of the biliary tract & 1.9 & 1.4 to 2.5 & $<0.001$ & 1.7 & 1.2 to 2.3 & 0.003 \\
\hline Pancreas & 2.0 & 1.8 to 2.3 & $<0.001$ & 1.7 & 1.4 to 2.0 & $<0.001$ \\
\hline Nasal cavity, middle ear and paranasal sinuses & 2.5 & 2.1 to 2.3 & $<0.001$ & 2.0 & 1.6 to 2.4 & $<0.001$ \\
\hline Larynx & 8.8 & 8.2 to 9.5 & $<0.001$ & 5.6 & 5.1 to 6.1 & $<0.001$ \\
\hline Bronchi and lung & 8.9 & 8.3 to 9.4 & $<0.001$ & 7.7 & 7.2 to 8.3 & $<0.001$ \\
\hline Kidney & 1.6 & 1.4 to 1.8 & $<0.001$ & 1.7 & 1.5 to 1.9 & $<0.001$ \\
\hline Bladder & 3.0 & 2.8 to 3.2 & $<0.001$ & 2.9 & 2.7 to 3.2 & $<0.001$ \\
\hline Central nervous system & 0.9 & 0.8 to 1.2 & 0.104 & 1.0 & 0.9 to 1.2 & 0.54 \\
\hline Thyroid & 0.7 & 0.6 to 0.8 & $<0.001$ & 0.7 & 0.6 to 0.9 & $<0.001$ \\
\hline Myeloid leukaemia & 1.0 & 0.9 to 1.1 & 0.347 & 1.0 & 0.8 to 1.1 & 0.70 \\
\hline Penis & 1.5 & 1.3 to 1.7 & $<0.001$ & 1.2 & 1.0 to 1.4 & 0.06 \\
\hline Prostate & 1.2 & 1.2 to 1.3 & $<0.001$ & 1.1 & 1.1 to 1.2 & $<0.001$ \\
\hline Testicle & 0.7 & 0.6 to 0.8 & $<0.001$ & 1.2 & 1.0 to 1.4 & 0.13 \\
\hline
\end{tabular}

vulva and vagina, the association was moderate and low, respectively. No studies that address the relationship between smoking and the risk of developing cancer of the vulva and vagina have been identified. For cervical cancer, the risk was moderate, which is consistent with the review of 23 epidemiological studies involving 13541 women, which found an increased risk for squamous cell carcinoma, although the same was not observed for adenocarcinoma. ${ }^{23}$ Regarding ovarian cancer, only the mucinous subtype seems to be positively associated with tobacco use; in this study the association for this tumour type was moderate, confirming the observations of a meta-analysis of 910 women with mucinous and 5564 with non-mucinous ovarian cancer, in which a risk for mucinous cases and lack of association for other subtypes was found. ${ }^{24}$ Among the remaining specific cancers in women, results of this study showed no association between smoking and the risk of developing cancer of the uterine body. However, even when considering the toxicity and carcinogenic effects of tobacco, the risk of endometrial cancer appears to be reduced. In another study, a protective effect of smoking was demonstrated with $28 \%$ reduction in the risk of endometrial cancer for women who consumed 20 or more cigarettes/day. ${ }^{25}$ Furthermore, the association did not vary with menopausal status, oral contraceptive use or hormone replacement therapy. When considering postmenopausal women with a higher body mass index, the protective effect was even more noteworthy. A European multicenter study involving 249986 female smokers, of whom 619 were diagnosed with endometrial cancer, also showed that tobacco consumption in postmenopausal women reduces the risk of disease, while moderate risk was found in premenopausal women. ${ }^{26}$ Tobacco use appears to reduce the risk of developing thyroid cancer, but the actual mechanism of this association needs to be better understood. Protection was observed for both genders, similar to the results of a prospective study involving 1003 participants who found a protective effect of smoking with a $32 \%$ reduction in risk for the general population, $17 \%$ for men and $37 \%$ for women. Moreover, the authors reported a decreased risk for the papillary subtype and possibly for the follicular subtype. $^{27}$

With regard to AF, a study with a similar design to that used here estimated the proportion of cancer cases related to exposure to tobacco and, in line with the results of the current study, showed values above $80 \%$ for most cancers of the respiratory tract, between $20 \%$ and $50 \%$ for digestive tract and lower urinary cancers. ${ }^{13}$ A Brazilian study also assessed the population attributable risk between smoking and developing some types of cancers and reported that the total elimination of smoking would reduce the risk of oesophageal cancer by $54 \%$, of lung cancer cases by $71 \%$, and of cancer of larynx by $86 \% .^{28}$ 
Table 5 Association between smoking and the development of different types of cancer in women

\begin{tabular}{|c|c|c|c|c|c|c|}
\hline \multirow[b]{2}{*}{ Cancer site } & \multicolumn{3}{|c|}{ Crude OR } & \multicolumn{3}{|c|}{ OR adjusted* } \\
\hline & $\overline{\text { OR }}$ & $95 \% \mathrm{Cl}$ & p Value & $\overline{\mathrm{OR}}$ & $95 \% \mathrm{CI}$ & p Value \\
\hline Oral cavity & 5.8 & 5.4 to 6.3 & $<0.001$ & 4.2 & 3.8 to 4.7 & $<0.001$ \\
\hline Oropharynx & 8.5 & 6.9 to 10.4 & $<0.001$ & 5.3 & 4.2 to 7.8 & $<0.001$ \\
\hline Nasopharynx & 2.2 & 1.8 to 2.8 & $<0.001$ & 1.8 & 1.4 to 2.4 & $<0.001$ \\
\hline Piriform sinus & 16.4 & 8.7 to 31.0 & $<0.001$ & 9.6 & 4.5 to 20.5 & $<0.001$ \\
\hline Hypopharynx & 7.6 & 5.5 to 10.4 & $<0.001$ & 4.4 & 3.0 to 6.4 & $<0.001$ \\
\hline Oesophagus & 6.3 & 5.7 to 6.9 & $<0.001$ & 4.2 & 3.7 to 4.7 & $<0.001$ \\
\hline Stomach & 2.3 & 2.2 to 2.4 & $<0.001$ & 1.8 & 1.6 to 2.0 & $<0.001$ \\
\hline Colon and rectum & 1.4 & 1.3 to 1.5 & $<0.001$ & 1.2 & 1.1 to 1.3 & $<0.001$ \\
\hline Anus and anal canal & 2.7 & 2.4 to 3.1 & $<0.001$ & 2.1 & 1.8 to 2.4 & $<0.001$ \\
\hline Liver & 1.9 & 1.5 to 2.3 & $<0.001$ & 1.4 & 1.1 to 1.9 & 0.004 \\
\hline Gallbladder & 1.5 & 1.2 to 1.9 & $<0.001$ & 1.2 & 1.0 to 1.6 & 0.01 \\
\hline Other parts of the biliary tract & 1.9 & 1.4 to 2.6 & $<0.001$ & 1.7 & 1.2 to 2.4 & 0.004 \\
\hline Pancreas & 2.1 & 1.8 to 2.5 & $<0.001$ & 1.9 & 1.6 to 2.3 & $<0.001$ \\
\hline Nasal cavity, middle ear and paranasal sinuses & 2.3 & 1.8 to 2.9 & $<0.001$ & 1.7 & 1.3 to 2.3 & $<0.001$ \\
\hline Larynx & 13.2 & 11.3 to 15.3 & $<0.001$ & 9.8 & 8.3 to 11.7 & $<0.001$ \\
\hline Bronchi and lung & 9.6 & 8.9 to 10.4 & $<0.001$ & 7.9 & 7.2 to 8.6 & $<0.001$ \\
\hline Kidney & 1.8 & 1.6 to 2.1 & $<0.001$ & 1.4 & 1.2 to 1.7 & $<0.001$ \\
\hline Bladder & 3.0 & 2.6 to 3.4 & $<0.001$ & 2.6 & 2.2 to 3.0 & $<0.001$ \\
\hline Central nervous system & 1.2 & 1.1 to 1.4 & 0.006 & 1.0 & 0.8 to 1.2 & 0.93 \\
\hline Thyroid & 0.9 & 0.8 to 1.0 & 0.005 & 0.8 & 0.7 to 0.8 & $<0.001$ \\
\hline Myeloid leukaemia & 1.3 & 1.1 to 1.5 & 0.001 & 1.0 & 0.9 to 1.2 & 0.74 \\
\hline Breast & 1.7 & 1.6 to 1.7 & $<0.001$ & 1.2 & 1.2 to 1.3 & $<0.001$ \\
\hline Vulva & 2.5 & 2.2 to 2.9 & $<0.001$ & 2.0 & 1.7 to 2.4 & $<0.001$ \\
\hline Vagina & 1.7 & 1.3 to 2.1 & $<0.001$ & 1.2 & 0.9 to 1.7 & 0.27 \\
\hline Cervix of uterus & 2.8 & 2.7 to 3.0 & $<0.001$ & 2.0 & 1.9 to 2.1 & $<0.001$ \\
\hline Uterine body & 1.0 & 1.0 to 1.1 & $<0.001$ & 1.0 & 0.9 to 1.1 & 0.54 \\
\hline Ovary (mucinous) & 2.2 & 1.7 to 2.7 & $<0.001$ & 2.1 & 1.6 to 2.7 & $<0.001$ \\
\hline
\end{tabular}

A limitation of this study is that it is based on the analysis of secondary data, with data collected in a large number of cancer treatment centres, making it difficult to standardise data collection. Moreover, we observed a high percentage of missing values for some variables. Such potential sources of bias were minimised by the Brazilian NCI through the construction of a web-based information system, the formulation and distribution of a manual of routines and proceedings, and the training of medical record technicians in order to standardise the collection and inputting of information. In addition, in its current version, the Integrator CHR System does not store detailed information on smoking history, being impossible to estimate the total lifetime dose or total dose in pack-years. Another limitation is that we used as control non-melanoma skin cancers that may have different behaviours in cases and controls taking into consideration skin colour, ethnic origin and geographical precedence.

A strong point worth mentioning is that the association between smoking and cancer was adjusted for alcohol consumption, another important determinant of the risk of developing cancer. Even with these limitations, the opportunity to define the magnitude of the risk of developing cancer associated with tobacco use and the fraction of cancers that can be attributed to its consumption by a large Brazilian national study allowed, for the first time in the country, a comprehensive overview of this association.

In conclusion, this study confirms a high risk of developing cancer of the hypopharynx, bronchi and lung, larynx, oropharynx and oral cavity, oesophagus and bladder cancer among smokers and establishes the AF attributable to smoking in the development of different types of cancers in Brazil.

Contributors MASM and SSA were involved in the analysis and interpretation of data, drafting of the article and final approval of the version to be published. AB and LCST were involved in the conception and design, critical revision for important intellectual content and final approval of the version to be published.

Funding This research received no specific grant from any funding agency in the public, commercial or not-for-profit sectors.

\section{Competing interests None.}

Ethics approval This study has been approved by the Ethics and Research Committee of the Brazilian National Cancer Institute, number CAAE0104.0.007.000-11.

Provenance and peer review Not commissioned; externally peer reviewed.

Data sharing statement No additional data are available.

Open Access This is an Open Access article distributed in accordance with the Creative Commons Attribution Non Commercial (CC BY-NC 3.0) license, which permits others to distribute, remix, adapt, build upon this work noncommercially, and license their derivative works on different terms, provided 
the original work is properly cited and the use is non-commercial. See: http:// creativecommons.org/licenses/by-nc/3.0/

\section{REFERENCES}

1. Boyle P, Levin B. eds. World Cancer Report 2008. Lyon, France: IARC Press, 2008. http://www.iarc.fr/en/publications/pdfs-online/wcr/ 2008/wcr_2008.pdf

2. Secretan $B$, Straif $\mathrm{K}$, Baan $\mathrm{R}$, et al. A review of human carcinogens, part E: tobacco, areca nut, alcohol, coal smoke, and salted fish. Lancet Oncol 2009;10:1033-4.

3. World Health Organization. WHO report on the global tobacco epidemic, 2013: enforcing bans on tobacco advertising, promotion and sponsorship. Geneva: World Health Organization, 2013. http:// apps.who.int/iris/bitstream/10665/85380/1/9789241505871_eng.pdf [accessed on 20 Nov 2013].

4. Levy D, Almeida LM, Szklo A. The Brazil SimSmoke policy simulation model: the effect of strong tobacco control policies on smoking prevalence and smoking-attributable deaths in a middle income nation. PLoS Med 2012;9:e1001336.

5. Almeida L, Szklo A, Sampaio M, et al. Global adult tobacco survey data as a tool to monitor the WHO Framework Convention on Tobacco Control (WHO FCTC) Implementation: the Brazilian case. Int J Environ Res Public Health 2012;9:2520-36.

6. Casado L, Thuler LCS. Tobacco prevalence in Brazil: a systematic review of population-based surveys. In: Luciani S, Vardy L, Paci E, Adewole I, Sasco A, Calvacante T. eds. Cancer prevention and population-based screening. Tumori: II Pensiero Scientifico Editore, 2009;95:597-609.

7. Rosenthal JA. Qualitative descriptors of strength of association and effect size. J Soc Serv Res 1996;21:37-59.

8. Gandini S, Botteri E, lodice S, et al. Tobacco smoking and cancer: a meta-analysis. Int J Cancer 2008;122:155-64.

9. Lee YC, Marron M, Benhamou S, et al. Active and involuntary tobacco smoking and upper aerodigestive tract cancer risks in a multicenter case-control study. Cancer Epidemiol Biomarkers Prev 2009;18:3353-61.

10. Wakai K, Inoue M, Mizoue T, et al. Tobacco smoking and lung cancer risk: an evaluation based on a systematic review of epidemiological evidence among the Japanese population. Jpn $J$ Clin Oncol 2006;36:309-24.

11. Ji X, Zhang W, Xie C, et al. Nasopharyngeal carcinoma risk by histologic type in central China: impact of smoking, alcohol and family history. Int J Cancer 2011;129:724-32.

12. Polesel J, Franceschi S, Talamini R, et al. Tobacco smoking, alcohol drinking, and the risk of different histological types of nasopharyngeal cancer in a low-risk population. Oral Oncol 2011;47:541-5.

13. Agudo A, Bonet C, Travier N, et al. Impact of cigarette smoking on cancer risk in the European Prospective Investigation into Cancer and Nutrition Study. J Clin Oncol 2012;30:4550-7.
14. Botteri E, lodice S, Bagnardi V, et al. Smoking and colorectal cancer: a meta-analysis. JAMA 2008;

300:2765-78

15. Leufkens AM, Van Duijnhoven FJ, Siersema PD, et al. Cigarette smoking and colorectal cancer risk in the European Prospective Investigation into Cancer and Nutrition study. Clin Gastroenterol Hepatol 2011;9:137-44.

16. Hunt JD, van der Hel OL, McMillan GP, et al. Renal cell carcinoma in relation to cigarette smoking: meta-analysis of 24 studies. Int $J$ Cancer 2005;114:101-8.

17. Jiang $\mathrm{X}$, Castelao JE, Yuan JM, et al. Cigarette smoking and subtypes of bladder cancer. Int J Cancer 2012; 130:896-901.

18. Lee $Y C$, Cohet $C$, Yang YC, et al. Meta-analysis of epidemiologic studies on cigarette smoking and liver cancer. Int $J$ Epidemiol 2009;38:1497-511.

19. Koh WP, Robien K, Wang R, et al. Smoking as an independent risk factor for hepatocellular carcinoma: the Singapore Chinese Health Study. Br J Cancer 2011;105:1430-5.

20. Batty GD, Kivimaki M, Gray L, et al. Cigarette smoking and site-specific cancer mortality: testing uncertain associations using extended follow-up of the original Whitehall study. Ann Oncol 2008;19:996-1002.

21. Watters JL, Park Y, Hollenbeck A, et al. Cigarette smoking and prostate cancer in a prospective US cohort study. Cancer Epidemio Biomarkers Prev 2009;18:2427-35.

22. Gram IT, Braaten T, Terry PD, et al. Breast cancer risk among women who start smoking as teenagers. Cancer Epidemiol Biomarkers Prev 2005;14:61-6.

23. International Collaboration of Epidemiological Studies of Cervical Cancer, Appleby P, Beral V, et al. Carcinoma of the cervix and tobacco smoking: collaborative reanalysis of individual data on 13541 women with carcinoma of the cervix and 23017 women without carcinoma of the cervix from 23 epidemiological studies. Int $J$ Cancer 2006;118:1481-95.

24. Jordan SJ, Whiteman DC, Purdie DM, et al. Does smoking increase risk of ovarian cancer? A systematic review. Gynecol Oncol 2006;103:1122-9.

25. Polesel J, Serraino D, Zucchetto A, et al. Cigarette smoking and endometrial cancer risk: the modifying effect of obesity. Eur $J$ Cancer Prev 2009;18:476-81.

26. Al-Zoughool M, Dossus L, Kaaks R, et al. Risk of endometrial cancer in relationship to cigarette smoking: results from the EPIC study. Int J Cancer 2007;121:2741-7.

27. Kitahara CM, Linet MS, BeaneFreeman LE, et al. Cigarette smoking alcohol intake, and thyroid cancer risk: a pooled analysis of five prospective studies in the United States. Cancer Causes Control 2012;23:1615-24.

28. Menezes AMB, Horta BL, Oliveira ALB, et al. Attributed risk to smoking for lung cancer, laryngeal cancer and esophageal cancer. Rev Saude Publica 2012;36:129-34 